\title{
UN SILENCIO OLVIDADO: LA POESÍA DE JUAN PERUCHO
}

Dolores Manjón-Cabeza Cruz

\section{RESUMEN}

En esta entrevista. Juan Perucho (de cuya muerte se cumple ahora el segundo aniversario) repasa aspectos poco conocidos de su extensa labor literaria: (a) los primeros escritos poéticos y críticos, en castellano y en catalám, en los que defendió teórica y prácticamente el surrealismo como opción estética; (b) sus relaciones con otros escritores en la Barcelona de posguerra (Néstor Luján. Antonio Vilanova, Juan-Eduardo Cirlot, Eugenio d'Ors, etc.): y (c), finalmente, la importancia de la poesía en la génesis de toda su obra.

Palabras Clave: Poesía de posguerra; España; Cataluña; Surrealismo; Juan Perucho.

\section{ZUSAMMENFASSUNG}

In diesem Interview mit Juan Perucho, dessen Tod sich zum zweiten Mal jährt, geht der Dichter nochmals einige bisher weniger bekannte Aspekte seiner intensiven literarischen Arbeit durch: (a) die frühen poetischen und kritischen Schriften in spanisch und katalanisch, in denen er theoretisch und praktisch den Surrealismus als ästhetische Idee verteidigt: (b) sein Verhältnis zu anderen Schriftstellern der Nachkriegszeit in Barcelona wie Néstor Luján, Antonio Vilanova, Juan-Eduardo Cirlot, Eugenio d'Ors, usw.; (c) und schließlich die Bedeutung der Poesie in der Entwicklung seines Oeuvres.

SCHLAGWORTE: Nachkriegsgedichte; Spanien; Katalonien; Surrealismus; Juan Perucho. 
La muerte de Juan Perucho a finales de octubre de 2003, acaecida entre la de Manuel Vázquez Montalbán y la del «poeta del pueblo» catalán Miquel Martí i Pol, pasó prácticamente desapercibida. Las exequias por Juan Perucho se celebraron en las más estricta intimidad y desde entonces han sido pocos los que han recordado las contribuciones de Perucho a la literatura catalana y a la literatura española; narrador, ensayista, crítico de arte y, por encima de todo, poeta, casi todas sus creaciones fueron vertidas por él mismo al castellano, aunque el catalán era su primera lengua. El éxito le vino sobre todo de la parte de las narraciones fantásticas, como Les històries naturals (1957, después profusamente traducida y reeditada); antes, se había volcado en la poesía, en libros como Sota la sang (1947), Aurora per vosaltres o Diana i la mar morta (en prosa poética). En esta entrevista, iniciada en el mes de abril de 2002 y continuada en marzo de 2003, indagamos en los inicios literarios de Perucho a principios de la década de los cuarenta, cuando el castellano era en Barcelona la única lengua posible.

Dolores Manjón: Sus primeros escritos, de crítica literaria y artística, fueron en las revistas del SEU Alerta y Estilo, donde defiende, como también hacen en esas publicaciones Antonio Vilanova y Néstor Luján, el surrealismo. ¿Cómo fue posible, en 1943, la apuesta por un movimiento tan subversivo?

Juan Perucho: Nosotros, por la proximidad con la frontera, íbamos y veníamos de Francia, buscando y comprando libros, íbamos frecuentemente, por ejemplo, a París. La poesía de aquel entonces ya no era surrealista del todo, pero pervivían unos extremos digamos surrealistas que nos impresionaron mucho. Empezamos a comprar libros surrealistas: Breton, Paul Eluard, y nos maravillamos, porque era descubrir el otro lado del espejo. Todo el mundo sabe lo que hay delante del espejo, nos vemos los ojos, las actitudes, pero llega un momento en que nos preguntamos: ¿qué hay detrás del espejo? Misterio. $\mathrm{O}$ no es un misterio, es una cosa que sólo los santos y los poetas saben, y es el gran misterio de la creación. ¿Cómo se ha hecho el mundo? ¿Qué es el mundo? Y no hay contestación intelectiva apropiada, y únicamente hay el surrealismo, que es una especie de conexión poética con la realidad de detrás del espejo. Yo estuve muy influido por el surrealismo, como todos mis compañeros. Un verso, un gran verso, no se puede explicar. «Polvo serán, mas polvo enamorado» ¿Cómo se puede explicar? Es como San Pablo, en cuyas cartas hay cosas impresionantes. Tienes la convicción de que ni él mismo sabe lo que dice, y llegas a la conclusión de que es la Verdad revelada. Y la revelación es el surrealismo.

D. M. Me gustaría saber cómo surgió Un silencio olvidado, un libro de poesía escrito en castellano en la década de los 40, aunque publicado mucho después, en 1993.

J. P. Yo llegué de la guerra y en la Universidad había unos grandes letreros que decían: «Si eres español, habla la lengua del imperio». Y entonces nos quedamos horrorizados Néstor Luján, Antonio Vilanova, Nani Valls, que era músico, Maurice Molho, un judío que vino de París huyendo de las tropas alemanas, Antonio Comas y yo. Forjamos una especie de grupo en el que nos interesamos por las dos culturas, por la cultura catalana y por la cultura castellana, porque nosotros éramos españoles y la forma nuestra de ser españoles era siendo catalanes, porque no podíamos ser madrileños. Nosotros fuimos casi los primeros; después vino Laye, con Ramón Carnicer, Sacristán, los Goytisolo, etc. 
Y estaban también las Entregas de Poesía, quizá lo más importante, dirigidas por Juan Ramón Masoliver, Diego Navarro y Julio Garcés, un gran poeta desaparecido. Pero llegó un momento en que tuvimos que elegir, porque estábamos resentidos por la política exclusivista en castellano que hacía el gobierno, y entonces yo me sentí totalmente abocado a la defensa de la lengua mía, la lengua coloquial mía, el catalán, e hicimos unas revistas en catalán, Ariel y Poesía. Como yo sentía una gran vocación para ser escritor, por escribir hubiera escrito en chino, así que me las arreglaba como podía. Tuvimos la oportunidad, Néstor Luján, Antonio Vilanova y yo de colaborar en Estilo, y Destino nos miraba con lupa porque creía que seríamos nosotros los que iríamos a sustituir las bajas que se producían. Y un día pasamos a Destino Néstor Luján, que con sus excepcionales dotes llegó a ser director, Antonio Vilanova, que hizo de crítico literario, un gran crítico, hasta que fue llamado por la Universidad de Madison en EEUU, y yo, que estuve diez años practicando la crítica de arte en Destino, con una página entera titulada «Invención y criterio de las artes». Pero al tiempo la creación literaria mía de verdad, aparte de los artículos, era en catalán, y publiqué una novela, Las historias naturales, traducida ya a 27 ó 28 idiomas, no sé, e hice también poesía en catalán y no tanto en castellano.

D. M. A mí me interesa mucho una cosa que señala Fernando Valls en el prólogo a Un silencio olvidado, y es que hay muchos rasgos surrealistas en ese libro, escrito entre 1943 y 1947. También en Sota la sang (1947). Algunos críticos incluso han señalado la existencia de un grupo, del que usted formaría parte, con significativos rasgos vanguardistas, el grupo «Guinea».

J. P. «Guinea» era un bar que había en la Diagonal esquina Lauria y Vía Layetana. Allí nos reuníamos un grupo de jóvenes poetas de la universidad y charlábamos. Tuvo una importancia relativa. De ahí surgió a principios de 1944 un libro muy curioso, titulado «9», porque nueve eran los amigos que aparecen retratados en él: Néstor Luján, yo, Francisco José Mayáns, José Riera, Nani Valls, Carlos Fisas, Ventura Torres, Antonio Vilanova y el dibujante José María de Martín. La introducción en verso, el «Zaguán», lo escribí yo. Se hicieron sólo 50 ejemplares. Eran tiempos felices, no sabíamos adónde iríamos a parar, pero esto nos estimulaba.

D. M. El «Zaguán» de 9, incluido después en Un silencio olvidado, posee una imaginería plenamente surrealista; empieza así «Cuando la mariposa latía en un pañuelo/ y la tinta era agua en todos los cristales/ y matamos, de una vez por todas, al fotógrafo.» ¿Eran conscientes de la marginalidad de sus propuestas poéticas?

J. P. Yo estuve a punto de publicar en el 43 Un silencio olvidado en la colección Barca Nueva, dirigida por el poeta Manuel Segalá. Pero la editorial se hundió y no pude publicarlo. Quedó en reserva, traspapelado, hasta que Vallcorba Plana se interesó por él y lo publicó, muy bien publicado, con un prólogo de Fernando Valls. [En Barca Nueva aparecieron, entre otros, La muerte de Gerión de Juan-Eduardo Cirlot, las Odas de Julio Garcés y los Poemas del amor eterno de R. E. de Goicoechea]. Néstor Luján intentó publicar El alba me traía una hoguera, que es un gran libro de poesía, y Francisco José Mayáns, Teresa diu de sobte que m' estima', pero no pudo ser. El libro de Néstor Luján lo sacó finalmente La Sirena, en tirada de 25 ejemplares.

' En realidad, se trata de un poema publicado en Ariel, VII-VIII, noviembre-diciembre de 1946. Francisco José Mayáns publicó más tarde Estancias amorosas (Adonais, 1949). 
D. M. Un numeroso grupo de poetas de principios de los cuarenta en Barcelona se aglutinó en torno a la revista Entregas de poesía, dirigida por Juan Ramón Masoliver; me refiero a Juan-Eduardo Cirlot, Manuel Segalá, Julio Garcés, José Cruset y otros. ¿Tenían contacto con ellos?

J. P. No, no mucho. Ellos escribían exclusivamente en castellano y nosotros en castellano y catalán, porque reivindicábamos lo nuestro. Nosotros pensábamos que después de la guerra lo que tenía que salvar al país era la juventud, con el entusiasmo que teníamos por el futuro, y que la juventud iba a convertir el país en otra cosa. Es el momento de mi participación en dos revistas poéticas semiclandestinas, Ariel y Poesía. Después vino Sota la sang (1947), que fue mi primer libro, en catalán. Hasta que después hemos visto que el país no se ha convertido en nada. Ha sido terrible. Mi forma de ser español es siendo catalán y tengo que reivindicar, por ejemplo, a Raimundo Lulio, que era el hombre que en su tiempo sabía más cosas del mundo. Nos ignorábamos cordialmente. Había con quien teníamos más contacto, al menos yo, como con Cirlot, que era también crítico de arte y defendíamos las mismas cosas.

D. M. A la tertulia que tenía Cirlot cerca de la Plaza Real, ¿fue usted alguna vez? Tengo entendido que en locales como «La Leona» o «La Jungla» se hablaba de Breton y se gestaban poemas (surrealistas) a dos, tres y hasta cuatro manos.

J. P. No. Cirlot y yo nos veíamos, él venía con frecuencia a casa y cuando sabía que iba a venir cogía los libros que parecía que le interesaban más y los escondía. Era terrible, espantoso, no los devolvía nunca. Con Juan Ramón Masoliver viajé a Rusia, junto con Carlos Casares, gallego, un jurista muy importante fallecido hace poco; fuimos a dar conferencias por todo el territorio soviético. Fue una experiencia extraordinaria.

D. M. ¿Recuerda a otros poetas de la época?

J. P. Sí, claro, a Luys Santa Marina, un hombre estupendo, magnífico, director entonces del Ateneo. Suspendió Alerta, pero antes me llamó. La revista iba en contra de todos los principios del régimen, y entonces Santa Marina era jefe de Prensa y Propaganda y me dijo: «Lo siento mucho, pero esto no puede seguir así»². Era muy buena persona, le salvó la vida a Carlos Riba, así como Carlos Riba también le salvó a él. Era un gran escritor. Tiene un libro de memorias [Perdida Arcadia] que es lo mejor de él. Y a Félix Ros, que dirigió una colección de poesía muy bonita, «Azor». Y por supuesto a Francisco Galí, compañero de colegio, poeta de haikús y editor primero (en su editorial Atzavara) de Diana i la mar morta.

D. M. ¿Y qué era la Academia del Faro de San Cristóbal?

J. P. Eugenio d'Ors compró en Villanueva y la Geltrú, hacia 1941, una sacristía adosada a la ermita de San Cristóbal y allí, un sitio precioso lleno de libros, cuadros, esculturas, ibamos muchos artistas. A mí me dieron el premio Ciudad de Barcelona [1953] y fui a dar las gracias al jurado, que era una cosa que antes se hacía y ya no; y al llegar al Presidente del Jurado, era Eugenio d'Ors, que vivía en la calle Sacramento de Madrid. Me abrazó y me dijo: «Mire, Perucho, cada uno en su vida tiene su destino y para eso se ha creado el Ángel Custodio, que no es más que la vocación o el destino». Me dejó, con esas palabras, clavado. «Usted tiene que ser escritor, de manera que...» «Pero es muy di-

${ }^{2}$ A pesar de las afirmaciones de Perucho, Luys Santa Marina no pudo suspender la publicación porque no tenía atribuciones para ello. 
fícil vivir de la poesía...» «Usted qué es?» «Yo soy abogado, pero no tengo ninguna vocación.» "Pues yo tengo un hijo que es Catedrático de Derecho Administrativo en Santiago de Compostela, y por él sé que ahora se han convocado oposiciones a judicatura.» «Pero yo no sé nada...»»Usted haga la instancia y me la manda a Madrid.» Y las saqué y gracias a eso llevo ya 100 libros publicados. Por la mañana yo iba al juzgado y por la tarde podía escribir todo el rato. A partir de ahí me hice muy amigo de Eugenio d'Ors, pero se me murió muy temprano. Como tenía tantos amigos y le iban a ver, dijo: «¿Por qué no hacemos una Academia?» $Y$ lo organizamos de forma que todo el mundo pudiera hablar a su tiempo, con orden. Y así nació la Academia del Faro de San Cristóbal, en el faro de Villanueva, en la ermita. Funcionó a partir de 1946 ó 1947. Fuimos mucha gente: Cirlot estuvo, Masoliver también, Cruset, y otros muchos poetas. Era un lugar de encuentro. Cuando se murió d'Ors continuó la Academia unos cuantos años más; se hacían las reuniones en la Diputación, en lo que hoy es el edificio de la Generalitat, pero eso ya fue a finales de los cincuenta.

Para terminar, Perucho busca en su biblioteca uno de los 25 ejemplares de Poemas de amor. El alba me traía una hoguera, el libro de zéjeles de Néstor Luján que, según recuerda Ridruejo ${ }^{3}$, siempre andaba bajo el brazo de su autor. Los poemas juveniles de Luján llevan la huella de Lorca ya en el título: «Zéjel de la muchacha asomada a mi sangre», "Dalia oscura», «La mujer ahorcada en un anillo», "Zéjel de la muchacha hallada en las hojas del árbol», etc. Son versos hermosos que nos revelan que en 1943 en Barcelona la poesía, aunque obligada al castellano, se había mantenido fiel a los principales hallazgos de antes de la guerra, entre ellos el surrealismo. También los versos de Juan Perucho, como éstos de la «Elegía» de Un silencio olvidado:

¿Dónde hallaré mi sombra que huye dilatada?

¿Y dónde tus cabellos que pudren violetas?

¿Y mi voz fallecida, segada eternamente? [...]

Pero mi voz ha muerto transmutada en sollozo,

segada ya por un frío de esquinas

y ladridos de perro.

Sirvan como recuerdo del gran poeta que Juan Perucho siempre fue las palabras de Andrés Trapiello (2003): «Perucho se valió siempre de la prosa para evadirse de este mundo, pero necesitaba de la poesía para volver a él».

\section{REFERENCIAS BIBLIOGRÁFICAS}

LuJÁn, Néstor (1943): Poemas de amor. El alha me traía una hoguera. Barcelona, La Sirena.

- y otros (1944): 9. Barcelona

- (1994): El túnel dels anys 40. Memòria personal. Barcelona, La Campana.

\footnotetext{
${ }^{3}$ En Casi unas memorias (1976: 268), Ridruejo cuenta que Luján fue a buscarlo con el libro a su cuarto de la calle Gerona a principios de 1944; según Ridruejo, formaba parte de un grupo de tres escritores que habían comenzado en Alerta y de los que Néstor Luján era «el más brillante y cabecero de la tríada».
} 
Mundo de Juan-Eduardo Cirlot (1996), Valencia, IVAM.

Perucho, Juan (1978): Poesia 1947-1973. Barcelona, Edicions 62.

- (1993): Un silencio olvidado. Poesía (1943-1947). Olot.

- (1993): Los jardines de la melancolía. Memorias. Valencia, Pre-textos.

RIDRUEJo, Dionisio (1976): Con fuego y con raices. Casi unas memorias. Barcelona, Planeta.

Trapiello, Andrés (2003): "Una rosa del desierto para J. P.», en La Vanguardia, 31 de octubre de 2003. 